\title{
Effects of pressure-controlled and volume-controlled ventilation on respiratory mechanics and systemic stress response during laparoscopic cholecystectomy
}

\author{
Oznur Sen ${ }^{1}$, Tarik Umutoglu², Nurdan Aydın , Mehmet Toptas ${ }^{1}$, Ayse Cigdem Tutuncu ${ }^{3}$ and Mefkur Bakan ${ }^{2 *}$
}

\begin{abstract}
Pressure-controlled ventilation (PCV) is less frequently employed in general anesthesia. With its high and decelerating inspiratory flow, PCV has faster tidal volume delivery and different gas distribution. The same tidal volume setting, delivered by PCV versus volume-controlled ventilation (VCV), will result in a lower peak airway pressure and reduced risk of barotrauma. We hypothesized that PCV instead of VCV during laparoscopic surgery could achieve lower airway pressures and reduce the systemic stress response. Forty ASA I-II patients were randomly selected to receive either the PCV (Group PC, $n=20$ ) or VCV (Group VC, $n=20$ ) during laparoscopic cholecystectomy. Blood sampling was made for baseline arterial blood gases (ABG), cortisol, insulin, and glucose levels. General anesthesia with sevoflurane and fentanyl was employed to all patients. After anesthesia induction and endotracheal intubation, patients in Group PC were given pressure support to form $8 \mathrm{~mL} / \mathrm{kg}$ tidal volume and patients in Group VC was maintained at $8 \mathrm{~mL} / \mathrm{kg}$ tidal volume calculated using predicted body weight. All patients were maintained with $5 \mathrm{cmH}_{2} \mathrm{O}$ positive-end expiratory pressure (PEEP). Respiratory parameters were recorded before and $30 \mathrm{~min}$ after pneumoperitonium. Assessment of $A B G$ and sampling for cortisol, insulin and glucose levels were repeated 30 min after pneumoperitonium and $60 \mathrm{~min}$ after extubation. The P-peak levels observed before $\left(18.9 \pm 3.8\right.$ versus $\left.15 \pm 2.2 \mathrm{cmH}_{2} \mathrm{O}\right)$ and during $(23.3 \pm 3.8$ versus $20.1 \pm 2.9 \mathrm{cmH}_{2} \mathrm{O}$ ) pneumoperitoneum in Group V( were significantly higher. Postoperative partial arterial oxygen pressure $\left(\mathrm{PaO}_{2}\right)$ values are higher $(98 \pm 12$ versus $86 \pm 11 \mathrm{mmHg}$ ) in Group PC. Arterial carbon dioxide pressure $\left(\mathrm{PaCO}_{2}\right)$ values $(41.8 \pm 5.4$ versus $36.7 \pm 3.5 \mathrm{mmHg})$ during pneumoperitonium and post-operative mean cortisol and insulin levels were higher in Group VC. When compared to VCV mode, PCV mode may improve compliance during pneumoperitoneum, improve oxygenation and reduce stress response postoperatively and may be more appropriate in patients having laparoscopic surgery.
\end{abstract}

Keywords: Mechanical ventilation, Airway pressure, Systemic stress response, Cortisol, Insulin

\section{Background}

Laparoscopic cholecystectomy has virtually replaced classical open cholecystectomy, but the increase in intraabdominal pressure due to pneumoperitoneum has some consequences. The cardio-pulmonary and metabolic changes during pneumoperitoneum are complex and

\footnotetext{
*Correspondence: mefkur@yahoo.com

2 Department of Anesthesiology and Reanimation, Bezmialem Vakif University Faculty of Medicine, Vatan Cad, 34093 Fatih, Istanbul, Turkey Full list of author information is available at the end of the article
}

associated with the level of intra-abdominal pressure (which gives rise to increases in airway pressures), duration of pneumoperitoneum, patient position and the ventilation mode (Marca et al. 1990; Cunningam and Brul 1993).

The most frequently used ventilation mode in general anesthesia is volume-controlled ventilation (VCV), which utilizes a constant flow to deliver a target tidal volume and ensures minute ventilation, may result in high airway pressures in laparoscopic surgery. Pressurecontrolled ventilation (PCV), which has been initially 
proposed in ICU patients with acute respiratory distress syndrome as an alternative to VCV (Davis et al. 1996), is less frequently employed in general anesthesia. With its high and decelerating inspiratory flow, PCV has faster tidal volume delivery and different gas distribution. The same tidal volume setting, delivered by PCV versus VC, will result in a lower peak airway pressure and reduced risk of barotrauma (Davis et al. 1996; Mercat et al. 1993; Campbell and Davis 2002).

We hypothesized that PCV instead of VCV during laparoscopic surgery could achieve lower airway pressures and reduce the systemic stress response. In this study, we have aimed at comparing the effects of $\mathrm{PCV}$ and VCV modes during laparoscopic surgery on respiratory mechanics, oxygenation, and hemodynamics, as well as blood cortisol and insulin levels, which has not been investigated before.

\section{Methods}

This prospective randomized controlled study was approved by the Institutional Review Board of Haseki Training and Research Hospital (Number: 131, Date: 18.06.2014, Istanbul, Turkey). The study was carried out according to the principles of declaration of Helsinki and all patients were asked for their signed and informed consent. Forty patients of $18-70$ years of age in the ASA I-II risk classification were included in the study. Patients with morbid obesity (BMI exceeding $30 \mathrm{~kg} / \mathrm{m}^{2}$ ), history of cardiac, pulmonary, hepato-renal, endocrine, cerebrovascular and neuromuscular diseases or thoracic surgery were excluded. Further, only those cases admitted to the operating theatre until 11:00 A.M. were included in this study. Patients were randomly selected, by opening sealed envelopes, to receive either the PCV (Group PC, $\mathrm{n}=20$ ) or VCV (Group VC, $\mathrm{n}=20$ ) mode of ventilation during anesthesia.

On arrival at the operating room, standard monitoring was applied consisting of ECG, pulse oximetry and temperature. Intravenous midazolam $0.03 \mathrm{mg} / \mathrm{kg}$ was administered. After Allen test and local anesthetic infiltration, a cannula was placed to the radial artery and arterial pressures were monitorized. Blood sampling was made for baseline arterial blood gases (ABG) analysis and for cortisol, insulin and glucose levels to assess the systemic stress response. Anesthesia was induced with propofol $2 \mathrm{mg} / \mathrm{kg}$ and fentanyl $2 \mu \mathrm{g} / \mathrm{kg}$. Rocuronium $0.6 \mathrm{mg} / \mathrm{kg}$ was given to facilitate tracheal intubation. Anesthesia was maintained with 0.5-1.0 MAC of sevoflurane in a mixture of oxygen and air $\left(\mathrm{FiO}_{2}: 50 \%\right)$. Fentanyl $0.5-1 \mu \mathrm{g} / \mathrm{kg}$ was added to maintain systolic arterial pressure within $\pm 20 \%$ of the baseline value. The ventilator parameters were set as respiratory rate: 12 breaths/min (constant during anesthesia); inspirium time/expirium time: $1 / 2$ and fresh gas flow
$1 \mathrm{~L} / \mathrm{min}$. Patients in Group PC were given pressure support to form $8 \mathrm{~mL} / \mathrm{kg}$ tidal volume (pressure support level was adjusted to maintain the same tidal volume during pneumoperitoneum); while Group VC was maintained at $8 \mathrm{~mL} / \mathrm{kg}$ tidal volume, both were calculated using predicted body weight. All patients were maintained with 5 $\mathrm{cmH}_{2} \mathrm{O}$ positive-end expiratory pressure (PEEP).

After intubation, before pneumoperitoneum, heart rate, arterial pressures, $\mathrm{EtCO}_{2}$, peak, plateau and mean airway pressures (P-peak, P-plateau, P-mean respectively) and dynamic compliance (C-dyn) levels were recorded. Pneumoperitonium was created by $\mathrm{CO}_{2}$ insufflation and intra-abdominal pressure was maintained at $14 \mathrm{mmHg}$ by means of an automatic insufflator. Thirty minutes after the pneumoperitonium, the respiratory and hemodynamic parameters were recorded again, and sampling for ABG, cortisol, insulin and glucose levels were repeated. Anesthesia was maintained until the end of surgery.

All patients wore anti-embolic stockings and received enoxaparin $40 \mathrm{mg}$ subcutaneous before surgery; tenoxicam $20 \mathrm{mg}$ IV after anesthesia induction; paracetamol $1 \mathrm{~g} \mathrm{IV}$ after gallbladder extraction; tramadol $100 \mathrm{mg}$ and ondansetron $8 \mathrm{mg}$ before extubation. Skin incisions were infiltrated with $15-20 \mathrm{ml}$ of bupivacaine $0.5 \%$ before closure. Neuromuscular blockade was antagonized with sugammadex $2 \mathrm{mg} / \mathrm{kg}$ and tracheal extubation was carried out when the patient was fully awake. Hemodynamic parameters were recorded and blood sampling for ABG, cortisol, insulin and glucose levels were repeated for the last time $60 \mathrm{~min}$ after extubation (without supplemental oxygen).

The primary outcome variable was P-peak levels during pneumoperitoneum. The sample size requirement was based on data from a previous retrospective study (Sen et al. 2014) in our institution with 80 patients in which P-peak levels were $24 \pm 2.9 \mathrm{cmH}_{2} \mathrm{O}$ in Group VC and $20 \pm 2.7 \mathrm{cmH}_{2} \mathrm{O}$ in Group PC. Thus, at an alpha risk of $0.05,20$ patients per group would provide $89 \%$ power and detect a $20 \%$ reduction in P-peak levels.

\section{Statistical analysis}

Windows program SPSS 15.0 was used for the statistical analysis of the results. Descriptive statistics were given in terms of numbers and percentages for categorical variables, and in terms of the mean, standard deviation and the median for the numerical variables. Comparison of two independent groups of variables was carried out using the Student $\mathrm{T}$ test when meeting the normal distribution criteria, or by the Mann-Whitney U test when these criteria were not met. Relationship between numerical variables was assessed by means of the Spearman Correlation Analysis. The differences between categorical 
variables were evaluated by the Chi square analysis. Statistical $\alpha$ (alpha) significance level was accepted with the 'p' value below 0.05 .

\section{Results}

Demographic parameters, pneumoperitoneum time and perioperative hemodynamic values of patients were closely comparable between groups (Table 1 ). Respiratory parameters during mechanical ventilation are shown in Table 2. Perioperative arterial blood gas analysis, lactate, cortisol, insulin and glucose levels are shown in Table 3. P-peak levels observed before and during pneumoperitoneum in Group VC were significantly higher when compared to Group PC. Before pneumoperitoneum, P-plateau level was higher in Group VC (17.2 \pm 3.5 versus $14.8 \pm 2.1 \mathrm{cmH}_{2} \mathrm{O}$ ).

Postoperative $\mathrm{PaO}_{2}$ values are higher in Group PC. Also, $\mathrm{PaCO}_{2}$ values during pneumoperitonium were higher and $\mathrm{pH}$ values during pneumoperitoneum and post-operative period were lower in Group VC. The mean post-operative cortisol and insulin levels were higher in Group VC. The mean preoperative glucose level was higher in Group VC, which was in normal limits.

\section{Discussion}

Major finding of the present study is PCV mode was associated with lower P-peak levels before and after pneumoperitoneum and reduced systemic stress

Table 1 Demographic

parameters and perioperative hemodynamic values

\begin{tabular}{lll}
\hline & $\begin{array}{l}\text { Group PC } \\
(\mathbf{n = 2 0 )}\end{array}$ & $\begin{array}{l}\text { Group VC } \\
(\mathbf{n = 2 0})\end{array}$ \\
\hline Age (year) & $49.7 \pm 10.8$ & $49.0 \pm 13.5$ \\
Weight (kg) & $74.2 \pm 9.3$ & $75.1 \pm 11.4$ \\
Gender (M/F) & $7 / 13$ & $8 / 12$ \\
Pneumoperitoneum time (min) & $45.2 \pm 21.6$ & $43.4 \pm 19.3$ \\
HR (beats/min) & & \\
PRE & $80.0 \pm 15.9$ & $75.6 \pm 5.9$ \\
PER & $90.2 \pm 15.7$ & $81.9 \pm 12.2$ \\
POST & $80.8 \pm 5.9$ & 84 \\
SAP (mmHg) & & \\
PRE & $135.4 \pm 16.8$ & $135.7 \pm 18.9$ \\
PER & $125.1 \pm 21.0$ & $127.9 \pm 23.9$ \\
POST & $114.4 \pm 13.0$ & $117.3 \pm 17.0$ \\
MAP (mmHg) & & \\
PRE & $112.2 \pm 17.1$ & $109.9 \pm 17.6$ \\
PER & $102.7 \pm 17.1$ & $100.0 \pm 20.0$ \\
POST & $93.6 \pm 12.8$ & $93.6 \pm 13.1$ \\
\hline
\end{tabular}

$H R$ heart rate, $S A P$ systolic arterial pressure, MAP mean arterial pressure, $P R E$ preoperative values, $P E R$ peroperative values (during pneumoperitonium), $P O S T$ postoperative values response postoperatively in patients having laparoscopic cholecystectomy. Also $\mathrm{PCO}_{2}$ levels during pneumoperitoneum were lower (this may be due to better gas distribution and ventilation/perfusion ratio) and postoperative $\mathrm{PO}_{2}$ levels were higher (this may indicate less alveolar derecruitment) in Group PC.

In similar studies: Tyagi et al. (2011) have observed lower P-peak values and higher compliance without any changes in $\mathrm{PaO}_{2}$ values; Gupta et al. (2012) also reported lower P-peak levels and dead space with higher $\mathrm{PaO}_{2}$ in the PCV mode. In the Balick-Weber study, (2007) passage from the VCV to the PCV mode resulted in a fall in the P-peak values and an increase in the compliance without any significant differences in oxygenation, systolic and diastolic heart functions. Ogurlu et al. (2010) have reported similar findings during laparoscopic gynecological operations. In similarly designed study with the obese (Cadi et al. 2008), recorded high $\mathrm{PaO}_{2}$ levels with low dead space values and without significant alterations in the P-peak, P-plateau and the P-mean values in the patients ventilated with $\mathrm{PCV}$ mode.

The lower P-peak levels during the PCV mode have been associated most frequently with in cases of acute lung injury, acute respiratory distress syndrome, and ventilation of the single lung. Observation of higher $\mathrm{PaO}_{2}$ levels in the PCV mode despite the application of equal tidal volume in both the PCV and the VCV

Table 2 Respiratory parameters during mechanical ventilation

\begin{tabular}{|c|c|c|c|}
\hline & $\begin{array}{l}\text { Group PC } \\
(n=20)\end{array}$ & $\begin{array}{l}\text { Group VC } \\
(n=20)\end{array}$ & $P$ \\
\hline \multicolumn{4}{|c|}{$\mathrm{EtCO}_{2}(\mathrm{mmHg})$} \\
\hline । & $30.2 \pm 1.7$ & $31.5 \pm 4.9$ & NS \\
\hline$\|$ & $33.1 \pm 1.8$ & $33.0 \pm 4.2$ & NS \\
\hline \multicolumn{4}{|c|}{ P-peak $\left(\mathrm{cmH}_{2} \mathrm{O}\right)$} \\
\hline । & $15.0 \pm 2.2$ & $18.9 \pm 3.8$ & $<0.001$ \\
\hline$\|$ & $20.1 \pm 2.9$ & $23.3 \pm 3.8$ & 0.007 \\
\hline \multicolumn{4}{|c|}{ P-plateau $\left(\mathrm{cmH}_{2} \mathrm{O}\right)$} \\
\hline । & $14.8 \pm 2.1$ & $17.2 \pm 3.5$ & 0.024 \\
\hline$\|$ & $19.9 \pm 2.6$ & $21.4 \pm 3.7$ & NS \\
\hline \multicolumn{4}{|c|}{ P-mean $\left(\mathrm{cmH}_{2} \mathrm{O}\right)$} \\
\hline 1 & $8.8 \pm 1.0$ & $9.2 \pm 1.0$ & NS \\
\hline$\|$ & $10.2 \pm 0.8$ & $10.2 \pm 1.1$ & NS \\
\hline \multicolumn{4}{|c|}{$\mathrm{C}$-dyn $\left(\mathrm{mL} / \mathrm{cmH}_{2} \mathrm{O}\right)$} \\
\hline । & $56.7 \pm 12.0$ & $42.7 \pm 9.8$ & $<0.001$ \\
\hline$\|$ & $38.0 \pm 7.0$ & $34.7 \pm 6.7$ & NS \\
\hline \multicolumn{4}{|c|}{$\begin{array}{l}E t \mathrm{CO}_{2} \text { end-tidal carbon dioxide, } P \text {-peak peak airway pressure, } P \text {-plateau plateau } \\
\text { airway pressure, } P \text {-mean mean airway pressure, } C \text {-dyn dynamic compliance, } \\
\text { I values after entubation, before pneumoperitonium, /I values during } \\
\text { pneumoperitonium, NS not significant }\end{array}$} \\
\hline \multicolumn{4}{|c|}{$p<0.05$ : statistically significant } \\
\hline
\end{tabular}


Table 3 Perioperative arterial blood gas analysis and systemic stress response

\begin{tabular}{|c|c|c|c|}
\hline & $\begin{array}{l}\text { Group PC } \\
(n=20)\end{array}$ & $\begin{array}{l}\text { Group VC } \\
(n=20)\end{array}$ & $P$ \\
\hline \multicolumn{4}{|c|}{$\mathrm{PO}_{2}(\mathrm{mmHg})$} \\
\hline PRE & $89.1 \pm 15.6$ & $85.0 \pm 15.0$ & NS \\
\hline PER & $155 \pm 32.3$ & $136.3 \pm 36.2$ & NS \\
\hline POST & $98.4 \pm 11.8$ & $86.3 \pm 11.3$ & 0.002 \\
\hline \multicolumn{4}{|c|}{$\mathrm{PCO}_{2}(\mathrm{mmHg})$} \\
\hline PRE & $37.3 \pm 5.6$ & $38.9 \pm 5.4$ & NS \\
\hline PER & $36.7 \pm 3.5$ & $41.8 \pm 5.4$ & 0.001 \\
\hline POST & $37.4 \pm 5.6$ & $39.0 \pm 5.3$ & NS \\
\hline \multicolumn{4}{|l|}{$\mathrm{pH}$} \\
\hline PRE & $7.41 \pm 0.04$ & $7.40 \pm 0.05$ & NS \\
\hline PER & $7.39 \pm 0.04$ & $7.35 \pm 0.05$ & 0.003 \\
\hline POST & $7.39 \pm 0.04$ & $7.37 \pm 0.04$ & 0.037 \\
\hline \multicolumn{4}{|c|}{ Cortisol (mg/dL) } \\
\hline PRE & $12.5 \pm 5.6$ & $14.2 \pm 6.2$ & NS \\
\hline PER & $22.4 \pm 5.6$ & $22.4 \pm 6.4$ & NS \\
\hline POST & $20.5 \pm 8.5$ & $27.5 \pm 5.9$ & 0.005 \\
\hline \multicolumn{4}{|c|}{ Insulin $(\mu \mathrm{U} / \mathrm{mL})$} \\
\hline PRE & $4.6 \pm 3.3$ & $5.8 \pm 3.7$ & NS \\
\hline PER & $3.2 \pm 2.8$ & $3.8 \pm 4.5$ & NS \\
\hline POST & $7.4 \pm 5.7$ & $11.6 \pm 6.3$ & 0.02 \\
\hline \multicolumn{4}{|c|}{ Glucose (mg/dL) } \\
\hline PRE & $89 \pm 9.0$ & $78 \pm 14$ & 0.004 \\
\hline PER & $112 \pm 22$ & $100 \pm 19$ & NS \\
\hline POST & $100 \pm 16.7$ & $109 \pm 20$ & NS \\
\hline \multicolumn{4}{|c|}{ Lactate (mmol/L) } \\
\hline PRE & $2.2 \pm 0.6$ & $2.8 \pm 0.8$ & NS \\
\hline PER & $2.8 \pm 0.5$ & $2.9 \pm 0.2$ & NS \\
\hline POST & $1.8 \pm 0.8$ & $2.5 \pm 0.7$ & NS \\
\hline
\end{tabular}

$P \mathrm{O}_{2}$ arterial oxygen pressure, $P \mathrm{CO}_{2}$ arterial carbon dioxide pressure, $P R E$ preoperative values, $P E R$ peroperative (during pneumoperitonium) values, $P O S T$ postoperative values, NS not significant

$p<0.05$ : statistically significant

group of patients may be associated with the higher plateau and mean airway pressure recordings. However, higher oxygenation has been observed in some studies despite lack of significant differences in the airway pressure values. The improved oxygenation in the PCV mode may be attributed to ventilation with a higher flow rate and square wave pressure. The elevated flow at the beginning of inspiration causes faster rise in the pressure compared to the VCV mode and the earlier supply of a higher proportion of the tidal volume. The fast alveoli with a short time constant may be overinflated at the start of the inspiration, but the subsequent homogenization of the tidal volume spread in the alveoli prevents the incidence of the development of atalectasis. Also, despite the lowering of the inspiratory flow rate during the plateau pressure phase, the flow never reaches zero as in the VCV (Abdullah et al. 2014). The better oxygenation may be related to these properties of the PCV.

In our study, high $\mathrm{PaCO}_{2}$ values recorded during the pneumoperitoneum with $\mathrm{VCV}$ and the lower postoperative $\mathrm{pH}$ values were nevertheless within the physiological limits. In both group of patients, the respiratory frequency was constant. As regards the systemic stress responses, the higher postoperative glucose levels of Group VC were, again, within the physiological range. The cortisol and insulin levels were both lowered postoperatively in Group PC.

Although involving different surgery than ours, it is relevant to consider here that during the weaning from cardiopulmonary bypass in patients undergoing aortacoronary bypass surgery, application of volume-targeted synchronized intermittent mandatory ventilation plus pressure support (SIMV + PS) or pressure-targeted bilevel positive airway pressure (BIPAP + PS) to two different group of patients did not result in significant differences in the post operative stress responses of the two groups (Calzia et al. 2001). However, it was observed that the BIPAP mode was more comfortable and the sedation requirements were reduced. $\mathrm{Hu}$ et al. (2014) compared the effects of VCV and pressure-controlled volumeguaranteed (PCV-VG) mode during one lung ventilation (OLV) on circulation, pulmonary function and lung injury. PCV-VG showed lower P-peak and higher compliance levels and also compared with VCV group, IL-6, and TNF- $\propto$ of PCV-VG were significantly lower. They concluded that during OLV in thoracoscopic lobectomy, PCV-VG mode has a competitive advantage over $\mathrm{VCV}$ mode in terms of pulmonary function and lung protection.

The lower systemic stress response and lung injury after PCV mode usage may be due to low peak pressure, high oxygenation and compliance results lower incidence of atelectasis.

The major limitation of our study is our groups were healthy subjects. The findings of our study may not be clinically significant, but discrepancy in clinical consequences can be expected in patients with poor pulmonary function. Also, the absence of any data regarding the transpulmonary pressure may be another limitation of this study.

\section{Conclusion}

According to our findings, when compared to $\mathrm{VCV}$ mode, PCV mode may improve compliance during pneumoperitoneum, improve oxygenation and reduce stress response postoperatively and may be more appropriate in patients having laparoscopic surgery. 


\section{Authors' contributions}

Author OS helped design the study, conduct the study, analyze the data, and write the manuscript. Author TU helped write the manuscript. Author NA helped conduct the study. Author MT helped conduct the study. Author ACT helped design the study. Author MB helped analyze the data, and write the manuscript. All authors read and approved the final manuscript.

\section{Author details}

'Department of Anesthesiology and Reanimation, Ministry of Health Haseki Training and Research Hospital, Istanbul, Turkey. ${ }^{2}$ Department of Anesthesiology and Reanimation, Bezmialem Vakif University Faculty of Medicine, Vatan Cad, 34093 Fatih, Istanbul, Turkey. ${ }^{3}$ Department of Anesthesiology and Reanimation, Istanbul University Cerrahpasa Medical Faculty, Istanbul, Turkey.

\section{Competing interests}

The authors declare that they have no competing interests.

\section{Ethical approval}

Informed consent was obtained from all individual participants included in the study.

Received: 23 December 2015 Accepted: 2 March 2016

Published online: 08 March 2016

\section{References}

Abdullah M, Al S, Mohamed R et al (2014) Right ventricular function during one-lung ventilation: effects of pressure-controlled and volume-controlled ventilation. J Cardiothorac Vasc Anesth 28(4):880-884

Balick-Weber CC, Nicolas P, Hedreville MM et al (2007) respiratory and haemodynamic effects of volume-controlled vs pressure-controlled ventilation during laparoscopy: a cross-over study with echocardiographic assessment. Br J Anaesth 99:429-435
Cadi P, Guenoun T, Journois D et al (2008) Pressure-controlled ventilation improves oxygenation during laparoscopic obesity surgery compaired with volume-controlled ventilation. Br J Anaesth 100(5):709-716

Calzia E, Koch M, Stahl W et al (2001) Stress response during weaning after cardiac surgery. Br J Anaesth 87(3):490-493

Campbell RS, Davis BR (2002) Pressure-controlled versus volume-controlled ventilation; What is matter? Respir Care 47:416-424

Cunningam AJ, Brul SI (1993) Laparoscopic cholecystectomy; anesthetic implications. Anesth Analg 76:1120-1133

Davis K Jr, Branson RD, Campbell RS, Porembka DT (1996) Comparison of volume control and pressure control ventilation: is flow waveform the difference? J Trauma 41 (5):808-814

Gupta SD, Kundu SB, Ghose T et al (2012) A comparison between volume-controlled ventilation and pressure-controlled ventilation in providing better oxygenation in obese patients undergoing laparoscopic cholecystectomy. Indian J Anesth 56:276-282

Hu X, Shen H, Li X et al (2014) Effects of volume-controlled ventilation and pressure-controlled volume-guaranteed mode during one-lung ventilation on circulation, pulmonary function and lung injury. Zhonghua Yi Xue Za Zhi 94(13):1006-1009

Marca AP, Yeo Cl, Rock P (1990) Anesthesia for patient undergoing laparoscopic cholecystectomy. Anesthesiology 73:1268-1270

Mercat A, Graïni L, Teboul JL, Lenique F, Richard C (1993) Cardiorespiratory effects of pressure-controlled ventilation with and without inverse ratio in the adult respiratory distress syndrome. Chest 104(3):871-875

Ogurlu M, Kucuk M, Sizlan A (2010) Pressure-controlled vs volume-controlled ventilation during laparoscopic gynecologic surgery. J Minim Invazive Gynecol 17:295-300

Sen O, Yilmaz F, Toptas M et al (2014) Laparoskopik Kolesistektomi Operasyonlarında Basınç kontrollü ve Volüm Kontrollü Ventilasyon Modlarınının Karşılaşıııılması. Med Bull Haseki 52:75-79. doi:10.4274/ haseki.1227

Tyagi A, Kumar R, Sethi AK, Mohta M (2011) A comparison of pressured-controlled and volume-controlled ventilation for laparoscopic cholecystectomy. Anaesthesia 66(6):503-508

\section{Submit your manuscript to a SpringerOpen ${ }^{\circ}$ journal and benefit from:}

- Convenient online submission

- Rigorous peer review

- Immediate publication on acceptance

- Open access: articles freely available online

- High visibility within the field

- Retaining the copyright to your article

Submit your next manuscript at springeropen.com 